\title{
Utilidad de la tomografía por emisión de positrones (PET) y biopsia del ganglio centinela (BGC) en el estadiaje cervical NO del carcinoma epidermoide orofaríngeo
}

J. D. Sánchez López*, E. Valencia Laseca*, M. A. Muros de Fuentes**, J. L. llamas Elvira**, J. M. Ruiz López**, A. Concha López ${ }^{* * *}$

\section{Resumen}

- Introducción: con los métodos diagnósticos actuales, la determinación de metástasis cervicales ocultas (pNO) de carcinoma escamosos orofaríngeo resulta sumamente dificultoso.

- Objetivos: el empleo de una nueva técnica diagnóstica evitará la realización innecesaria de disecciones cervicales.

- Técnica: proponemos la realización de la identificación mediante linfogammagrafía del ganglio centinela, su posterior evaluación histopatológica y la realización de la tomografía por emisión de positrones (PET) en la evaluación de metástasis cervicales ocultas (pNO).

Palabras clave:

Ganglio centinela. PET.

Oncología, 2004; 27 (8):505-509

* Servicio de Cirugía Oral y Maxilofacial

** Servicio de Medicina Nuclear

*** Servicio de Anatomía Patológica

Hospital Universitario "Virgen de las Nieves". SAS.

Granada 


\section{Summary}

- Introduction: The detection of occult nodal metastases in patients with oropharyngeal squamous cell carcinoma is not enough precise employing the traditional diagnostic procedures.

- Objective: The use of new appropriate diagnostic techniques will avoid an unnecessary number of neck dissections.

- Technique: We propose the performance of the sentinel lymph node radiolocalization, the pathological study of the sentinel node, and the use of positron emission tomography (PET) for the evaluation of occult neck metastases.

Key words: Sentinel lymph node. Positron emission tomography. PET.

\section{Introducción}

El carcinoma de la cavidad oral representa actualmente el $4 \%$ de las neoplasias malignas en el hombre y el $2 \%$ en la mujer, cifras similares a las presentadas por el carcinoma de páncreas y el melanoma, constituyendo aproximadamente el $30 \%$ del total del carcinoma escamoso de cabeza y cuello. En la Comunidad Autónoma de Andalucía y concretamente en la provincia de Granada representa el 1,2\% del total de carcinomas en hombres y el $4 \%$ en mujeres'.

Dicho carcinoma se considera una auténtica enfermedad regional por su tendencia a diseminar a través de los canales linfáticos a los ganglios linfáticos (GL) cervicales. La presencia de metástasis ganglionares linfáticas cervicales (MGC) va a provocar un descenso de la supervivencia en un $50 \%$, siendo el estadiaje cervical correcto de gran importancia para predecir el pronóstico y programar el tratamiento ${ }^{2}$.

Actualmente, las técnicas de diagnóstico por imagen no permiten detectar de forma exacta la presencia de metástasis ganglionares cervicales, lo que ha motivado la realización rutinaria de linfadenectomías cervicales profiláctico-diagnósticas de estadiaje, la mayoría de las cuales son ineficaces al no existir afectación ganglionar en el estudio histopatológico $(\mathrm{pNO})^{3}$.

La técnica de la biopsia del ganglio centinela (BGC), tras mostrar su eficacia en el melanoma cutáneo y en el cáncer de mama, representa hoy día uno de los principales métodos de estadiaje cervical, pudiéndose llegar a convertirse en el procedimiento de elección. Dicha técnica se fundamenta en el hecho de que el estado histopatológico de/los GC refleja el estado del resto de los ganglios cervicales, de este modo, se obtendrá el estadiaje cervical a través de una biopsia mínimamente invasiva, reduciéndose la morbilidad, tiempo quirúrgico y estancia hospitalaria ${ }^{4,5}$. Por otra parte la tomografía por emisión de positrones
(PET), basada en cambios metabólicos de los tejidos presenta una mayor sensibilidad que los métodos tradicionales (TAC y RMN) en la evaluación cervical clínicamente negativa (NO) ${ }^{6-8}$ (Fig. 1).

Unificando ambos prodedimientos diagnósticos en una única técnica pretendemos alcanzar los siguientes objetivos.

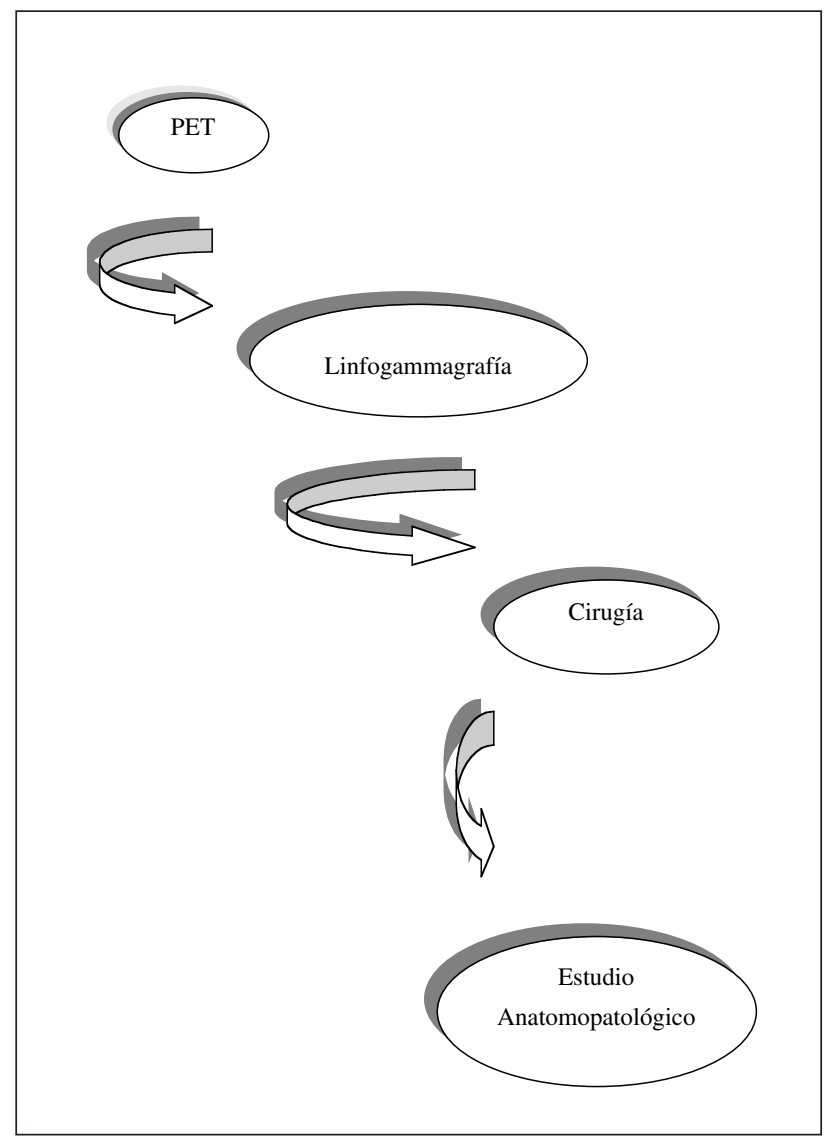

Fig. 1. Técnica combinada de BGC y PET. 


\section{Objetivos}

1. Validar la técnica de la BGC como método de estadiaje cervical en pacientes con carcinoma epidermoide oral y estadio cervical NO.

2. Determinar la eficacia del PET en el estadiaje cervical de cuellos NO.

3. Conocer y comprobar los índices de rendimiento diagnóstico de cada una de las técnicas (exploración física, TAC, PET) empleadas en la valoración de la extensión cervical del carcinoma epidermoide oral.

4. Comprobar, si la técnica se muestra útil, cuál es la indicación más costo-eficiente para la realización del PET.

5. Conocer los costes reales de las distintas técnicas diagnósticas de valoración cervical.

\section{Material y métodos}

Diseño: estudio de carácter observacional y prospectivo de una cohorte que incluirá a los pacientes diagnosticados en el Servicio de Cirugía Oral y Maxilofacial del H.U. Virgen de las Nieves de carcinoma epidermoide de cavidad oral con estadio cervical NO en los que el tratamiento consistirá en la realización de una extirpación del tumor primario y posterior disección cervical (DC), con independencia del estadio clínico del tumor primario. Los tumores deben de estar comprobados histológicamente, estadiados clínicamente y radiológicamente y accesibles para la inyección de del radiotrazador. Se comparará el rendimiento diagnóstico del procedimiento diagnóstico habitual (exploración física y TAC) con la aplicación del PET y BGC.

\section{Criterios de inclusión}

1. Confirmación histopatológica de carcinoma epidermoide primario de cavidad oral (l

2. Estadio cervical NO. (Confirmación clínica y Tomográfica).

3.- Tratamiento quirúrgico estándar: resección y reconstrucción del tumor primario y realización de $\mathrm{Di}$ sección Cervical.

4. Consentimiento informado y autorización por escrito para participar.

Materiales: se dispondrá del personal y equipamiento del Servicio de Medicina Nuclear del Hospital Universitario "Virgen de las Nieves" donde se realizarán los estudios de PET. El reclutamiento, intervención quirúrgica y posterior seguimiento de los pacientes se- rá realizado por parte del Servicio de Cirugía Oral y Maxilofacial del mencionado Centro, tras la valoración clínica del estado cervical, dicha información será contrastada mediante la realización de un TAC cervical, interpretado por al menos dos observadores independientes. Posteriormente, el Servicio de Anatomía Patológica realizará los estudios de las piezas quirúrgicas tanto cervicales como del tumor primario según la técnica protocolizada en dicho Servicio. Aunque el protocolo propugnado por la mayoría de los autores para el estudio de los GC es variable, incluye 2 técnicas especiales: 1. Seccionamiento múltiple y tinción con hematoxilina-eosina y 2 . Tinción inmunohistoquímica utilizando anticitoqueratinas AE1/AE3. Asignaremos un código numérico a cada GC en función de sus hallazgos histopatológicos y de inmunohistoquímica, de forma similar al Estudio Multicéntrico Internacional de la BCG en el Carcinoma Epidermoide Oral y Orofaríngeo del hospital de Canniesburn en Escocia9 (Fig. 1).

\section{Detalles técnicos}

1. Linfogammagrafía: Gammacámara Picker Axis2 de doble detector.

El día anterior a la intervención, administración de 3-4 inyecciones peritumorales de $10 \mathrm{MBq}$ de $99 \mathrm{~m}$ Tcmicrocoloide de albúmina (Albu-Res) de $0,5 \mathrm{mml}$ de volumen, con una pureza radioquímica de al menos un $95 \%$.

\section{PET: Tomógrafo PET Siemens ECAT Exact.}

Las imágines de emisión se obtienen a los 30 minutos de la administración de la FDG, 11 minutos por posición de la camilla, incluyendo cráneo, cuello, tórax y región epigástrica. Posteriormente se obtienen

TABLA I

Valor diagnóstico de las distintas pruebas
en la evaluación cervical del carcinoma orofaríngeo

\begin{tabular}{lcc}
\hline Estadiaje cervical & Sensibilidad (\%) & Especificidad (\%) \\
\hline Examen clínico & 71 & 75 \\
PET & $72-91$ & $88-98$ \\
TAC & $40-68$ & $65-100$ \\
RMN & $41-80$ & $82-88$ \\
Ecografía & $50-58$ & $75-82$ \\
PAAF-Ecografía & $42-73$ & 100 \\
Biopsia intraoperatoria & 90.5 & 100
\end{tabular}


las imágenes de emisión utilizando una fuente en forma de anillo GE 8.

\section{TAC: Equipo Philips Secura}

Se administrarán $15 \mathrm{cc}$ de constraste a $4 \mathrm{mml} / \mathrm{sg}$ con retraso de $10 \mathrm{seg}$.

\section{Variables}

1. Independientes: datos del paciente (edad, sexo, hábitos tóxicos...) y del tumor primario (clasificación TNM, profundidad tumoral, grado de diferenciación,...).

2. Dependientes: número de ganglios tumorales detectados por PET y BGC y características ganglionares ( rotura capsular, necrosis...).

\section{Período de seguimiento}

Todos los pacientes se revisarán durante un período de 5 años o hasta su fallecimiento, mediante revisiones semestrales, practicándose control clínico y radiográfico.

\section{Análisis de los resultados}

Se contrastará la eficacia diagnóstica del PET y $B G C$ en relación al empleo de métodos convencionales (TAC y exploración cervical) en el diagnóstico precoz de afectación metastásica en tumores NO.

Correspondencia:

Dr. J. D. Sánchez López

C/ Martínez Campos, 23 - 6 B

E-18002 Granada

E-mail: dario@fundación.hvn.org

\section{Bibliografía}

1. Parkin DM, Laara E, Muir CS. Estimates of the worlwide frequency of sixteen major cancer in 1990. Int J Cancer 1998; 41:184-97.

2. Mamelle G, Pumperik J, Luboinski B et al. Lymph node prognostic factors in head and neck squamous cell carcinomas. Am J Surg 1994; 168: 494-8.

3. Shah JP, Andersen PE. The impact of patterns of nodal metastases on modification of neck dissection. Ann Surg Oncol 1994; 1:521-32.

4. Zitsch RP, Todd DW, Renner GJ et al. Intraoperative radiolymphoscintigraphy for detection of occult nodal metastasis in patients with head and neck squamous cell carcinoma. Otolayngol Head Neck Surg 2000; 122:662-6.

5. Alex JC, Sasaki CT, Krag DN, Wenig B et al. Sentinel lymph node radiolocalization in head and neck squamous cell carcinoma. Laryngoscope 2000; 110:198-203.

6. Aassar S, Fischbein N, Caputo $G$ et al. Metastaci head and neck cancer: role and usefulness of FDG PET in locating occult primary tumors. Radiology 1999; 210:17781.

7. Lowe V, Boyd J, Dunphy F et al. Surveillance for recurrent head and neck cancer using PET. J Clin Oncol 2000; 18:651-8.

8. Agencia de Evaluación de Tecnologías Sanitarias (AEFTS). Instituto de Salud Carlos III. Ministerio de Sanidad y Consumo. Tomografía por Emisión de Positrones (PET) con 18 FDG en Oncología Clínica (Revisión Sistemática). Madrid: AETS-Instituto de Salud Carlos III, Noviembre de 2001.

9. Ross G. Multicentre Interventional Trial of Sentinel Node Biopsy in Oral and Oropharyngeal Cancer. Canniesrburn Plastic Surgery Unit. www. Canniesburn.org.2000. 